\title{
Participación de los/as niños/as y democratización en la escuela: apertura y limitaciones
}

\section{Lucía Rodríguez Bustamante ${ }^{1}$}

\author{
Ilnstituto de Ciencias Antropológicas, Facultad de Filosofía y Letras, Universidad de Buenos Aires, Ciudad \\ Autónoma de Buenos Aires, Argentina. \\ ORCiD: 0000-0002-9894-7942 \\ Correo electrónico: luciarodriguezbustamante@gmail.com
}

Recibido:

mayo de 2019

Aceptado:

febrero de 2020

doi: 10.34096/runa.v41i1.6280

\section{Resumen}

Al restablecerse el estado de derecho después de la última dictadura en Argentina (1976-1983) se hizo de principal importancia afianzar y fortalecer la democracia en las instituciones educativas. Desde ese momento, la creación de espacios de participación estudiantil en escuelas secundarias aumentó considerablemente. Sin embargo, en el nivel primario existe aún cierta vacancia en lo que refiere a la presencia de órganos de participación. Es posible argumentar que dicha situación se asienta en las concepciones naturalizadas que definen a los/as niños/as como sujetos sin autonomía de pensamiento y sin capacidad de participación en la cotidianeidad escolar.

A partir de la reconstrucción y el análisis de un Consejo de grado en una escuela primaria pública de la Ciudad Autónoma de Buenos Aires durante 2016-2017, mediante un enfoque histórico etnográfico, se documentan y analizan los procesos de apropiación y el sentido que los/as niños/as y docentes expresan en torno a la participación en este espacio.

\section{Participation and democratization in primary school: opening and limitation}

\begin{abstract}
When the rule of law was restored after the last dictatorship in Argentina (1976-1983), it became of main importance to consolidate and strengthen democracy in educational institutions. From that moment, the creation of spaces for student participation in secondary schools increased considerably. However, at the primary level there is still a certain vacancy related with participation spaces. It is possible to argue that this situation is based on the naturalized
\end{abstract}

\section{Palavras-chave}

Ciudadanía; Política; Infancia; Formación; Apropiación

\section{Key words}

Citizenship; Politic; Childhood; Education; Appropriation 
conceptions that define children as subjects without autonomy of thought and unable to participate in school daily life.

From the reconstruction and analysis of a Grade Council in a public elementary school in the Ciudad Autónoma de Buenos Aires during 2016-2017, through an historical ethnographic approach, the processes of appropriation and meaning expressed by children and teachers are documented and analyzed around participation in this space.

\section{Participação e democratização na escola primária: abertura e limitações}

\section{Resumo}

Palavras-chave

Cidadania; Política; Infancia; Treinamento; Apropriação
1. El material que se trae a análisis a lo largo del artículo es producto del trabajo de campo realizado entre septiembre de 2016 a diciembre de 2017, y está compuesto por registros de interacción y charlas informales mantenidas con los/ as sujetos durante este período.
Quando o estado de direito foi restaurado após a última ditadura na Argentina (1976-1983), tornou-se de primordial importância consolidar e fortalecer a democracia nas instituições educacionais. A partir desse momento, a criação de espaços para a participação dos alunos nas escolas secundárias aumentou consideravelmente. No entanto, no nível primário ainda há uma certa vacância quanto à presença de órgãos de participação. Pode-se argumentar que essa situação é baseada nas concepções naturalizadas que definem as crianças como sujeitos sem autonomia de pensamento e sem capacidade de participar do cotidiano escolar.

A partir da reconstrução e análise de um Conselho de Grau em uma escola pública de ensino fundamental na Cidade Autônoma de Buenos Aires durante o período de 2016-2017, através de uma abordagem etnográfica histórica, os processos de apropriação e significado expressos por crianças e professores são documentados e analisados em torno da participação neste espaço.

\section{Introducción}

"Los niños no son considerados como miembros sociales en una situación plena y regular. Son mirados como candidatos, son colocados en la lista de los que esperan" John Dewey (1978, p. 64).

El presente artículo profundiza sobre la participación en la escuela, y las apropiaciones que docentes y niños/as hacen de ella en la puesta en práctica de un Consejo de grado que funciona hace diez años en una escuela estatal primaria de la Ciudad Autónoma de Buenos Aires. ${ }^{1}$ Mediante un enfoque histórico etnográfico se busca comprender y documentar los sentidos que los protagonistas les dan sus prácticas, los debates y confrontaciones en torno a estas, a la vez que se reconstruyen las lógicas de los procesos histórico-sociales en las que se insertan como vía de explicación de su permanencia y/o quiebres (Batallán, 1998; Achilli, 2005; Rockwell, 2009).

Tradicionalmente, el espacio escolar ha sido concebido como políticamente neutral, característica que se vincula fuertemente con los supuestos en torno a los sujetos que lo constituyen: niños/as y maestros/as. Esto contribuye a reconocer su particularidad como institución, en la que, además de confluir 
(conflictivamente) el Estado y la sociedad civil (docentes y familias) (Ezpeleta y Rockwell, 1983), centra su razón de ser en los/as niños/as, los/as que paradójicamente, por su estatus de menores, son el sujeto excluido de la participación (Batallán, 2011). Al asumir el desafío de reconstruir los modos en que los/as niños/as habitan activamente el espacio escolar, la investigación recupera los aportes de la teoría de la estructuración de Anthony Giddens, y en especial la reflexión en torno al concepto de "agencia" como categoría analítica, entendida como la "capacidad de actuar de otra manera" (1982, p.10). El enfoque, que hace base en el estudio de procesos de la cotidianeidad de la vida social, resulta sumamente pertinente para el estudio de prácticas invisibilizadas como son las diversas acciones que los/as niños/as despliegan en pos de la organización de la institución escolar (Rockwell, 2009). El registro documental de sentidos y prácticas en el campo se desarrolla considerando que los interlocutores con quienes se trabaja son "intérpretes polémicos" de su propia realidad (Batallán y García, 1992). Asentados en esta premisa, el desarrollo de un abordaje dialógico habilita a la producción de sentidos coconstruidos con los/as sujetos, acción que implica ubicar en el centro de análisis el carácter performativo del lenguaje (Batallán, 2019). En concordancia con ello, a lo largo del artículo se reconstruirán diversos intercambios y debates entre niños/as y docentes en torno a la justicia, la democracia y la participación en el espacio escolar.

La investigación en torno a procesos de democratización en las escuelas guarda una larga tradición de estudios sociales (Cigliutti, 1993; Tiramonti, 1993; Dussel, 2005; Batallán y Campanini, 2008; Enrique, 2011; Batallán y Campanini, 2012; Núñez, 2013; Castro, 2018). Lo que resulta principalmente problemático es que, si bien el objetivo de la institución escolar apunta a la formación ciudadana democrática, esta se dirige hacia otro tiempo, otro espacio y otro sujeto. Frente a esta impronta fundante, y a la reactualización de tales sentidos en el presente, encarar el objetivo de formar en ciudadanía es una tarea a la que se le superponen diversas dimensiones y tradiciones que la vuelven problemática e invitan a reflexionar en torno a sus sentidos naturalizados.

La incorporación de la Convención de los Derechos del Niño en Argentina, y en diversos países del mundo, instituyó un importante cambio al concebir a los/ as niños/as y adolescentes como sujetos de derecho. No obstante, se advierte que esta no significó una transformación radical, especialmente en lo que refiere al reconocimiento de su participación (Pupavac, 2001; Barna, 2012; Liebel, 2013). A pesar de que en la normativa esté expresada la importancia de la opinión de los/as niños/as, se presenta una tensión entre la autonomía y la protección infantil, ya que el/la niño/a no es considerado el agente moral que determina el alcance de sus derechos (Padawer, et al., 2009; Barna, 2012; Shabel, 2016). En este marco investigadores retoman esta tensión y critican las posibilidades que los espacios de participación organizados en el ámbito educativo y coordinados por docentes puedan llegar a tener (Tiramonti, 1993; Liebel, 2007).

La hipótesis que organiza este artículo supone que a partir de la noción de participación se manifiesta una tensión entre algo que debe ser aprendido y enseñado pero que, por su falta de ejercicio en la escuela primaria, entra en duda de si debe ser efectivamente practicado. La experiencia de espacios de participación de estudiantes no resulta demasiado extendida en este nivel y no ha logrado una adhesión generalizada del cuerpo docente, a pesar de contar con antecedentes a principios y mediados del siglo XX como en escasas experiencias en los años 80 y $90 .^{2}$
2. Las experiencias de gobiernos escolares o tribunales infantiles iniciadas por maestros como Carlos Vergara y Florencia Fossatti para principios y mediados del siglo XX son antecedentes de estas propuestas; acciones que se vieron interrumpidas desde el Estado por "precipitar la infantilidad" (Carli, 1992, p. 141). Estas propuestas tuvieron cierto resurgimiento para fines de los años ochenta en formatos como consejos de grado o asambleas, aunque tampoco lograron extenderse de forma masiva (Golzman y López, 1989). 
Creemos que el supuesto sobre la incapacidad o inadecuación de la participación en la educación primaria remite a sentidos profundamente arraigados en torno a la política, la infancia y la escuela. Por un lado, la política ha sido considerada una ocupación casi exclusiva de los hombres adultos; por el otro, la infancia se constituyó, para fines del siglo XVII, como una edad diferenciada y opuesta a la adultez (Ariès, 1987). La noción restringida de la política, entendida como aquellos mecanismos de participación formal en las instituciones, excluye a los/ as niños/as y genera la imposibilidad de su participación ya que no cuentan con el estatus de ciudadanos (Adorno, 1973; Batallán y Campanini, 2008). En este proceso, será la escuela la principal institución participante en coconstruir la noción de infancia como etapa de preparación para la vida adulta. La política -en su sentido más formal, y debido a su carácter conflictivo- es ubicada por fuera del mundo escolar (Batallán, 2011; Campanini, 2018).

Detenernos a trabajar sobre esta problemática en niños/as que cursan sus estudios primarios no es una tarea sencilla; de hecho, supone complejizar aún más el planteo. A diferencia del nivel secundario, donde los jóvenes adolescentes son mayormente reconocidos como actores políticos (Enrique, 2011; Núñez, 2013, Campanini, 2018), los/as niños/as que cursan sus estudios primarios resultan, en lo que refiere al ejercicio político, excluidos (Batallán, 2011). De hecho, la invisibilización de estos sujetos en los estudios etnográficos ha sido muy extendida hasta las décadas de los ochenta y noventa, que es cuando lentamente comienzan a ser entendidos como sujetos en "sí mismos" (Jociles, Franzé y Poveda, 2011). Cabe aclarar que, según lo ha detallado Andrea Szulc, su posterior incorporación como sujetos activos ha generado que en muchas investigaciones se sobredimensionara su accionar, por lo que enfatiza la necesidad de detenerse en el registro de su acción social situada en la trama de relaciones de poder en cada contexto sociohistórico (2019).

De este modo, nos preguntamos: ¿qué implica la participación en una institución estatal bajo responsabilidad adulta como es la escuela, y qué sentidos se ponen en juego cuando los/as niños/as tienen un lugar central? La puesta en práctica de este espacio nos invita a preguntarnos ¿quiénes tienen el derecho a participar?; ¿cuáles son las aptitudes que habilitan para dicho ejercicio?; ¿qué supone ser una persona educada en ciudadanía? En definitiva, ¿cómo puede pensarse la democratización de una institución que está constituida por menores? Y, retomando a Dewey (1978), ¿cómo tensionar el lugar de los/as niños/as "como candidatos" para verlos como protagonistas en la producción de la vida social cotidiana del espacio escolar y, por tanto, social?

\section{Entre la tradición disciplinaria y la apertura democrática: ¿que supone abrir la participación en la escuela?}

Las corrientes constructivas y su desarrollo pedagógico se han instalado como estrategia de enseñanza y aprendizaje de las distintas disciplinas que atraviesan el espacio escolar en la actualidad. El hecho de incorporar la práctica como modo de aprendizaje resulta parte de muchas de las propuestas que los/ as docentes despliegan en el aula. Sin embargo, cuando hablamos de participación en el espacio escolar, numerosos sentidos se presentan superpuestos (Cerletti, 2012).

Es así que esta investigación decidió recuperar la experiencia de una escuela que propone un Consejo de grado como modalidad para abordar la formación ciudadana en términos de un "ejercicio práctico de la convivencia y en la 
participación grupal activa", como se detalla en su proyecto institucional. La elección de documentar el Consejo permitía registrar los debates entre niños/as y docentes en torno a la organización del espacio escolar, pero también contar con un espacio en el que el "tema de la participación" estuviera constantemente en debate. En el siguiente apartado abordaremos dos situaciones que buscan sumergirse en los debates que niños/as y docentes despliegan en relación con la participación en la escuela.

\section{El debate entre docentes: el perfil del/la consejero/a, un cargo ejemplar}

En la escuela № 27, los/as consejeros/as de primero a séptimo se reúnen semanalmente. ${ }^{3}$ Juan, el maestro motorizador del Consejo, y las directoras del establecimiento coordinan el evento; sin embargo, los/as principales protagonistas son los chicos/as. ${ }^{4}$ Unos minutos antes de entrar al Consejo General están en sus aulas, con sus maestras y compañeros/as, probablemente sentados, hablando, escribiendo, leyendo, haciendo lo que se espera de estudiantes de primaria. Pero unos meses atrás, cuando fueron elegidos por votación de sus compañeros/as, estos estudiantes se convirtieron también en los/as consejeros/as de sus grados. Esto supone tareas diferentes a las de otros/as estudiantes: son los responsables de llevar los temas que se tratan en los Consejos de Aula al Consejo General, y de representar y velar por los intereses de quienes los eligieron: sus compañeros/as. ${ }^{5}$ Los temas que los convocan son variados, generalmente el recreo, sus juegos y espacios son los más recurrentes. Estos son los grandes asuntos que preocupan y conllevan horas de debate y organización para estos/as consejeros/as-estudiantes.

Para los/as docentes que lo coordinan supone algo novedoso; de hecho, el desarrollo de este espacio conlleva una constante negociación y reflexión sobre qué sentidos tendrá. Como adelantamos, las experiencias de consejos de grado o asambleas no se encuentran fuertemente instituidas en los espacios educativos; por ello, a la hora de ponerlos en práctica, la propuesta de abrir a la participación comienza a producir ciertos movimientos en el sentido más tradicional del rol docente. Como consecuencia, se tensionan y producen desconciertos que instan a que los docentes deban debatir por los sentidos y alcances de la propuesta.

Durante mi estadía en la escuela pude presenciar el desarrollo de la elección de los consejeros. Según las diversas charlas mantenidas con las maestras y directoras, todos los años, a comienzo del ciclo lectivo se llevan a cabo las elecciones. La escuela propone que para tal fecha las maestras dediquen algunas clases a trabajar "el perfil del consejero"; así, en un Consejo General se debatía:

La directora, que ese día moderaba el debate les pregunta a todos/as “ ¿Ya fueron eligiendo representantes? ¿qué dijimos que tienen que ser los consejeros?”. Los/ as estudiantes van respondiendo consecutivamente "ser ejemplo", " mostrar cumplir las normas"; una niña de segundo grado pregunta al Consejo "¿qué quiere decir 'ser ejemplo'?" La directora le responde "mostrar que entendés y respetás las normas". Los/as niños/as siguen pronunciando características "ser honesto, generoso", "solidario", "poder charlar con los demás", "ser bueno", "no hay que pegar, no dar patadas". La directora va afirmando a medida que se van agregando características; los/as niños/as continúan: "no ser falso, no ser mala persona, no decir malas palabras". La directora interrumpe y les pregunta "¿qué más había dicho Camila (una consejera)?", a lo que la niña interpelada agrega: "transmitir y llevar las ideas de acá (en referencia al Consejo General)". Finalmente, Juan cierra el intercambio diciendo "se acuerdan que el año pasado pasaba que las seños nos
3. La escuela cuenta con un grado por año (de primero a séptimo) y se encuentra ubicada en un barrio urbano-residencial de la ciudad. A ella asisten un total aproximado de 170 estudiantes, que provienen de familias de sectores medios y medios bajos.

4. Los nombres que aparecen a lo largo de todo el artículo, así como el número de la escuela, son ficticios con el fin de mantener el anonimato de los sujetos con quienes se investiga.

5. El Consejo de grado se divide en dos instancias: por un lado el Consejo de Aula, que es coordinado por la maestra a cargo del grado y donde se ponen en diálogo y debate distintas problemáticas que los/ as niños/as presentan. El segundo momento es el Consejo General, frecuentemente coordinado por Juan y por ambas directoras. Allí, los dos representantes de cada grado (de primero a séptimo -previamente elegidos por votación-) tratan y discuten colectivamente diversos temas que atañen a la escuela en general. 
6. Las elecciones se hacen de modo secreto y obligatorio, $y$ contemplan la opción de votar en blanco. decían que cuando les preguntaban ‘¿de qué hablaron?’, muchos decían ‘No sé, de nada', y es importante que digan qué es lo que se habla en el Consejo (General)” (Registro de Campo № 2,Consejo General, Escuela № 27, mayo 2017)

Con la intención de acompañar a los/as niños/as, los docentes exponen distinto tipo de explicaciones. Por un lado, se trata de informar a los/as estudiantes sobre las tareas que supone el cargo de consejero, como por ejemplo, "transmitir las ideas al grado", pero por otro, aparece una enumeración de valores y cualidades que remiten a conductas ejemplares.

En consecuencia, los/as consejeros/as suelen estar más observados respecto de su comportamiento, tanto por las/os docentes como por los/as otros/as consejeros/as y compañeros/as. Todas las características señaladas por los/as niños/ as evidencian justamente la construcción de un ideal que en la práctica resulta muy difícil de sostener para cualquiera; circunstancia que da pie a múltiples reflexiones entre los diversos protagonistas escolares.

Durante este proceso de elección de precandidatos/as y su posterior votación me llamó la atención una conversación que tuve con algunos/as docentes. Una de ellas manifestaba la preocupación porque una niña, que hasta ese momento había sido consejera y muy participativa, no había quedado preseleccionada, a diferencia de un niño, que suele ser más bien "rebelde", u otra estudiante que "es muy tímida". Frente a ello, Juan, el maestro que coordina el espacio, insiste en que es importante "ver lo que ellos traen", refiriéndose a los/as alumnos/as: "hasta ahora veníamos direccionando nosotros, veamos qué es lo que traen".

Este intercambio evidenció una tensión respecto del Consejo como espacio de democratización y el rol de los docentes allí: ¿cuánto respetar las elecciones inesperadas, a veces incontroladas, propias de la apertura presentada, y cuánto velar por lo que -se supone-lo mejor para un funcionamiento deseado? Yolanda Corona Caraveo y María Morfín Stoopen advierten que abrir a la participación no es simplemente oír lo que los chicos tienen para decir, sino que requiere de un esfuerzo por reconocer otra visión y hacerle un lugar (2001). En tal sentido, la afirmación de Juan perfila la potencia democrática de este espacio: respetar las elecciones de los/as niños/as, supone un encuentro de los docentes y estudiantes con lo democrático en su sentido más pleno, el de lo imprevisto (Masschelein y Simons, 2011).

Las elecciones de candidatos inesperados nos evidencia que, a pesar de la insistencia en reforzar ciertas cualidades, no existe una correlación directa con las selecciones efectivas que los/as niños/as terminan por realizar. ${ }^{6}$ De hecho, a lo largo de los años, los "perfiles" de los consejeros han sido sumamente diversos: si bien algunas veces fueron elegidos los/as buenos/as estudiantes, en muchas ocasiones fueron niños/as que no coincidían necesariamente con quienes mejor se portan, pero sí con quienes suelen animarse a enfrentar a sus docentes. Así, a la hora de elegir a sus candidatos ponen en juego otras apreciaciones, aún desconocidas, pero que ponen de manifiesto la imposibilidad de los/las docentes de anticiparlas y direccionarlas.

\section{Deliberaciones entre niños/as: el tratamiento del conflicto en el Consejo General}

Como espacio de toma de decisiones y puesta en marcha de numerosas acciones que remiten a la vida escolar cotidiana, el conflicto forma parte intrínseca del funcionamiento del Consejo, y se constituye en un potente analizador de 
la regulación de la interacción entre niños/as sobre distintas posturas con respecto a su propia participación, como del uso y el sentido dados a las nociones naturalizadas sobre el orden político y social.

El siguiente fragmento de un debate mantenido entre niños/as documenta cómo interpretan y evalúan el accionar de sus compañeros en estrecha vinculación con las intervenciones de los/as docentes. En los intercambios se condensan nociones estructurales de lo social y, específicamente, sobre qué supone ser un buen representante y cómo se debe actuar y participar en el Consejo y en la escuela en general.

Al comienzo de una sesión del Consejo General, el maestro le preguntó a una de las consejeras de séptimo grado por qué estaba tan seria. Luego de insistirle, la niña comentó: "Porque no sé para qué venimos si igual hay gente que no entiende nada". Frente a tal respuesta, el maestro le preguntó “¿Por qué? A ver, me interesa”. La niña prosiguió: "Que hay gente que viene al Consejo que no entiende bien las cosas que se dicen, las dicen mal o no hacen lo que pautamos". El maestro le responde "Qué bueno que puedas decir esto, porque también para eso está este espacio, ahora plantealo así tal cual me lo dijiste a mí, así lo discutimos entre todos".

La sesión, como de costumbre, se desarrollaba en el momento del desayuno; estábamos sentados en ronda alrededor de un banco alargado donde estaba el yogurt y las galletitas de vainilla. Al inicio de la sesión, la niña vuelve a plantear el asunto. "Hay consejeros que lo del Consejo lo explican mal o no lo entendieron. Creen que por ser consejeros pueden hacer las cosas mal sin que los reten, o se toman atribuciones. Se ve en algunos consejeros [...] dice que 'él es el consejero' y rompe las reglas acá".

Por la forma en que la niña habla se evidencia que se refiere a un chico presente en el espacio. Apoyando a esta queja, un niño de segundo grado interrumpe la conversación y dice "Vi a chicos jugando a 'la pelea', a él lo vi", al mismo tiempo que señala a un niño de quinto grado. La reacción no se hace esperar y en ese mismo momento el maestro y la vicedirectora lo interrumpen y le dicen. "No señales de ese modo, así no". (Registro de Campo № 4, Consejo General, Escuela № 27, octubre 2016)

Ambas intervenciones plantean un conflicto, un desacuerdo entre los/as participantes. Por un lado, existe una denuncia de abuso de poder, de "tomarse atribuciones" por ocupar el cargo de consejero, a partir de una concepción particular del rol, y establece un disenso sobre lo que para otro compañero significa "ser consejero". Si retomamos a Rancière (1996), podríamos decir que el desacuerdo que señala la niña no es solamente sobre lo que significa "ser consejero", sino también sobre una cuestión más profunda, sobre quiénes pueden y tienen derecho a litigar por ello (Etchegaray, 2014). En este sentido, la niña pone en tensión la legitimidad de su cargo, que no se agota en haber sido elegido por sus compañeros, sino que se trata de una función que se encuentra en constante evaluación. En más de una ocasión, varios niños/as me manifestaron disconformidad respecto del accionar de algunos/as estudiantes como consejeros/as.

Asimismo, al escuchar las afirmaciones y el modo en que la niña planteaba la acusación, el estudiante de segundo grado había identificado que se estaba haciendo referencia a alguien que estaba presente en el espacio. El modo en que se desarrollaba la conversación era el socialmente aceptable. Por el contrario, el niño puso en evidencia que allí se estaba realizando un señalamiento hacia alguien, pero utilizó una modalidad que fue marcada como inapropiada. En 
este acto evidenció la sutileza con la que se desarrollaba una acusación y una puesta en duda del accionar de alguien allí. En tal sentido, el conflicto o desacuerdo no remite simplemente a un nivel discursivo, sino que hace referencia a cuestiones más profundas, como son las disputas por quién ocupa un cargo de poder en la escuela.

Dicho intercambio permitió también comprender que los modos adecuados de participar son parte de lo que allí se enseña. El aspecto formativo incluye no solamente el qué decir sino cómo hacerlo, y este resulta parte fundamental del aprendizaje político y ciudadano en la escuela.

En el contexto escolar, la supuesta inmadurez atri:buida a los/as niños/as suele justificar la naturalización o evitación de un elemento constitutivo de lo social: el conflicto. Sin embargo, como fue brevemente señalado, los/as niños/ as constantemente lo ponen en juego como parte de la interacción con otros/ as; no se trata de una característica excepcional, sino que se lo recupera como experiencia cotidiana y constitutiva de estar con otros/as. Más allá de que se busquen explicaciones que señalan a sujetos individuales, su tratamiento en un espacio de construcción colectiva como es el Consejo posibilita reponer el sentido social del conflicto y, por ello también, aunque de modo indirecto, permite contrastar las concepciones que individualizan sus causas.

En particular, la construcción de un espacio de debate y diálogo como es el Consejo de Grado busca generar un escenario común de encuentro entre adultos/ as y niños/as, en el cual la diferencia por los roles escolares que ocupan no resulte un limitante. Este esfuerzo cobra su real trascendencia bajo la óptica de Rancière. El autor plantea que este es el propósito de la política; es decir, la creación de un escenario de interlocución común, donde el que ya tiene reconocido su lugar de participación en la sociedad acepte que aquel que no tiene ningún título es igual, en el sentido de que comprende y es capaz de ser comprendido y escuchado y que, por ello, debe ser tenido en cuenta (Etchegaray, 2014).

Sin embargo, la tarea de democratizar el espacio escolar tiene implicancias más bastas que, desarrolladas en profundidad, generan fuertes tensiones en las tradiciones sobre las que la escuela se sostiene; entre ellas, el vínculo de minoridad entre niños/as y adultos y su estructuración de acuerdo con las responsabilidades institucionales asumidas. El Consejo es un lugar de reconocimiento del otro -en este caso el niño/a- como capaz de dirimir y participar en la organización de algunos asuntos, pero es genuina la preocupación respecto de la naturaleza y el alcance de las decisiones en torno a las cuales pueden decidir los/as estudiantes.

En el siguiente apartado profundizaremos en las particularidades en que se desarrolla el debate entre niños/as y adultos en el Consejo. Como adelantamos, si bien este espacio es un escenario de encuentro, solo algunos temas son considerados legítimos de discutir. Y en este caso no serán únicamente los adultos quienes decidan qué se debate, sino que, como se desarrolla a continuación, también serán los niños/as quienes realizarán tales disquisiciones.

\section{Disputas políticas en torno a un tiempo perdido: el recreo y sus juegos}

En la división de los tiempos de la escuela, el recreo resulta el momento de esparcimiento, cuando los/as niños/as se distienden de muchas de sus tareas y responsabilidades que los/as implican como estudiantes: la prolijidad, el 
silencio, la escucha atenta a un docente, etc. Sin embargo, esto no supone que durante el recreo se puede hacer cualquier cosa: este también conforma al momento escolar. Existen, en su devenir, reglas implícitas y explícitas entre los/as niños/as y docentes que permiten el funcionamiento de juegos simultáneos, que se ven interrumpidos $\mathrm{y}$, a veces, conviven en una suerte de trama relacional. Coincidimos entonces con los estudios que evidencian cómo el recreo se construye como un momento de lo común (De Castro, 2018) y que a continuación desarrollaremos.

Un móvil importante para la creación del espacio de Consejo en la escuela fue el intento de organizar los juegos del recreo. Según sus maestras, debido a que no cuentan con una gran estructura edilicia que permita la simultaneidad de actividades, antes de que estuviera este espacio "los chicos salían lastimados, había accidentes permanentemente". De este modo, "el recreo y sus juegos" se presenta como un tema abiertamente reconocido y legitimado para ser debatido allí.

En principio, que los juegos sean llevados a discusión y evaluación en el Consejo genera tensiones para los/as niños/as; las negociaciones que allí se dan permiten reconocer el ejercicio político que se despliega detrás. Este debate no supone únicamente que se elaboren pautas, acuerdos y reglas sobre sus juegos; es también un espacio para consensuar propuestas que de otro modo hubiesen estado prohibidas:

\begin{abstract}
Mara, la consejera de quinto grado, es una niña cuya voz no suele escucharse mucho en el Consejo, sin embargo esa mañana me sorprendió. La estudiante escuchaba atenta cómo la directora comentaba algunas cuestiones del recreo y sus juegos, sobre los juguetes que los/as niños/as de primer ciclo usan en el recreo. Mara aprovecha una pausa que hace la directora y en voz baja pregunta tímidamente "que lo de los juguetes, si se puede jugar, los de quinto grado, si podemos jugar". La directora la mira y dice en voz fuerte "No". Inmediatamente hace una pausa, la mira nuevamente y continúa "habíamos dicho que no, que era solo para primer ciclo, en todo caso podemos revisarlo y pensar si podemos hacer algo para que los de segundo ciclo también jueguen [con juguetes]”. (Registro de Campo № 2, Consejo General, Escuela № 27, mayo 2017)
\end{abstract}

La reconstrucción de este fragmento muestra cómo la apropiación del Consejo por parte de los/as niños/as les permite encontrar una grieta sobre la que accionar; identificar puntos sobre los cuales están dispuestos a resistir y negociar. Como bien señala Rockwell, muchos de los modos en que esta resistencia se produce en la escuela no remiten a una confrontación abierta con la/el docente. Por lo general, los/as niños/as, conscientes de su lugar subalterno en este espacio, eligen hacer preguntas y sugerencias que, aunque a simple vista parecen tímidas, suponen importantes procesos de agenciamiento (2011).

En el registro de diversos intercambios de las maestras con los/as niños/as, y en la observación de momentos del recreo, he podido documentar cómo estos/as inventan juegos que no fueron consensuados en el Consejo, y eligen, deliberadamente practicarlos a escondidas de las maestras. Este espacio a veces es recuperado por algunas docentes como argumento para evitar el desarrollo de algunas acciones que descubren y consideran inadecuadas a la voz de "este juego no se acordó en el Consejo". Otras veces, estos resultan espontáneos y no interrumpen el funcionamiento del recreo, por tanto no son siquiera descubiertos; algunos de ellos se perpetúan en el tiempo y otros desaparecen al instante. 
Sin embargo, son los/as mismos/as chicos/as quienes reconocen que algunas propuestas no son tan adecuadas para el lugar físico con el que cuentan en la escuela. Así, en una oportunidad, un consejero de séptimo grado comentó un nuevo juego, similar a otro que está instaurado en la escuela, conocido como "Manobol", pero que consideraba más apropiado:

Luciano había empezado a comentar un juego cuando una maestra lo interrumpe y menciona "yo tengo que intervenir casi siempre durante el poscomedor cuando juegan al manobol, porque si bien hay un área, la pelota se termina saliendo del área y todos van a buscarla, son como cuatro (niños/as) atrás de la pelota y ahí se arma lío". Luciano, el consejero de séptimo, luego de escucharla, le aclara que no se trata del mismo: "pero este juego tiene eso de distinto, porque como es un juego cooperativo dejamos pasar la pelota entonces no conviene correr atrás de la pelota". Juan interviene con cierto entusiasmo: "es interesante lo que dice Luciano de pensar en juegos que sean cooperativos, y no de competencia. Por ejemplo, el juego del nudo... es un juego donde nadie gana, es en equipo (Registro de Campo № 4, Consejo General Escuela № 27, junio 2017)

Como evidencia este intercambio, los/as niños/as tienen algo para decir; cuentan con una experiencia y una reflexión sobre su realidad cotidiana que aporta a la construcción de un espacio común y a su regulación. En el fragmento citado, Luciano despliega estrategias para defender su propuesta que, sabe, será bienvenida en el espacio escolar: los juegos cooperativos. Asimismo, los aportes realizados en este espacio no son pensados de modo individual sino que, como también los estudios de Lucia Rabello de Castro documentan, los niños evidencian el carácter "colectivo de esta experiencia" (2018, p. 142).

En este sentido, vemos que los/as niños/as se apropian del espacio de Consejo y deciden qué propuestas poner en discusión y cuáles evitar, para iniciar, a propósito de estas, una negociación de sentidos políticos más profundos como es la organización de espacios y tiempos comunes.

\section{La construcción de acuerdos colectivos o la pregunta por ¿qué hacer?}

Como otras instancias que se desarrollan en la escuela, las maestras recuperan situaciones cotidianas a partir de las cuales deciden transmitir valores o contenidos educativos; el recreo y sus juegos es, por lo tanto, uno más de los emergentes para tal fin. Como se adelantó, existen cuestiones que son "discutibles" y otras que están por fuera de toda negociación. Algunas situaciones en las que niños/as y docentes trabajaron conjuntamente en la planificación del cotidiano escolar da cuenta de estas múltiples perspectivas:

A fin de año en la escuela se hizo un día de jornada especial del Consejo de Grado. Participaban todos los/as chicos/as de todos los años (primero a séptimo). Cada maestra trabajaba con grupos de veinte chicos/as aproximadamente, conformados por integrantes de todos los grados. Cada grupo trabajó con una o dos maestras temáticas distintas: Los derechos del niño, El respeto por el otro/a, etc. A lo largo de la mañana pude acompañar a dos grupos de chicos/as y maestras. En uno de ellos se plantearon los derechos que ellos/as creían que no se respetaban en la escuela; un niño dijo "derecho a jugar con la compu", otra niña dijo en voz baja "uy, isabes la lista que tengo!"; otro niño dijo "el juego de la botellita"; otro dijo "correr"; otro agrega "yo juego al pistolero". La maestra les pregunta “¿cómo creen que se puede solucionar?". Un niño responde: "encarcelar a los que se portan mal” y otro "el rinconcito de los castigados". (Registro de Campo № 10, Consejo General Escuela № 27, noviembre 2016) 
Desde la escuela se presenta el espacio para que los/as niños/as expresen su opinión en relación con sus "derechos". La maestra intenta, por un lado, que distingan entre aquellas prácticas posibles de ser reguladas y aquellas que ponen en riesgo su integridad: "si corremos nos podemos lastimar" decían más adelante. Los/as niños/as, en las soluciones a los conflictos, reponen sentidos y prácticas reactualizadas cargadas de historicidad, provenientes de la tradición disciplinar y autoritaria de la escuela y la sociedad. La maestra, entonces, orienta el desarrollo en la búsqueda de acuerdos institucionales:
La docente insiste "para revertir hay que respetar las normas" Un niño la interrumpe "con el juego de la botellita, se puede establecer la regla de que cuando uno va a tirar se alejan así no sufren un accidente". Otro niño agrega "se puede armar un lugar apartado". En ese momento, la directora se había acercado al grupo y propone "a ver si entre todos podemos armar una norma, una pauta, así se puede jugar". La maestra agrega "la botellita... a ver, ¿con qué otros juegos que no había en la escuela se pueden comparar?". Los/as niños/as van respondiendo "penales", otro dice "manobol". La docente repregunta "¿y qué hicimos para incorporarlos?" los/as niños/as agregan "un espacio en el patio", "un afiche”. Finalmente, la maestra agrega "a ver si el año que viene lo podemos reglar, para incorporar juegos sectorizados en el patio. (Registro de Campo № 10, Consejo General Escuela № 27, noviembre 2016)

En este intercambio es posible reconocer cómo las ideas que los/as niños/as presentan son orientadas por la docente en el sentido de que apelen a la regulación a partir de acuerdos y normas, de respeto por los derechos, y de juegos que no los pongan en riesgo. A partir de la puesta en común, se buscaba la incorporación del "juego de la botellita", que todo ese año había estado prohibido por "no garantizar la seguridad de los/as niños/as". De este modo, al mismo tiempo que ejercen su participación se los intenta formar en la propuesta de crear acuerdos compartidos. A lo largo de distintos intercambios mantenidos en el Consejo, también fue posible reconocer el implícito sentido del contrato con los/as niños/as, propio de los discursos psicopedagógicos que, para fines del siglo XX, fueron haciéndose lugar en las escuelas, y que desplazaron los modos autoritarios heredados de la dictadura por formas reflexivas e individualizadas (Dussel, 2005). En los intercambios registrados, los/as niños/as demuestran conocer los acuerdos, normas y pautas como modo de regular las prácticas cotidianas:

Una maestra me cuenta entusiasmada "recién fue genial, estábamos viendo lo de las reglas del manobol y un nene de segundo me dice (lo imita) "podemos poner un árbitro que rote semanalmente". Sorprendida me comenta "iviste! el pibe ya había planeado todo, cuándo tenía que rotar el árbitro, itodo!”.(Registro de Campo № 10, Consejo General Escuela № 27, noviembre 2016)

Asimismo, los/as estudiantes en sus intervenciones en el Consejo de General y los Consejos de Aula constantemente plantean estrategias sobre el espacio escolar común, especialmente porque conocen las dificultades que cotidianamente deben afrontar y se reconocen capaces de revertirlas, como lo es, por ejemplo, la falta de espacio en el patio.

Cuando niños/as y adultos se reúnen para resolver una verdadera pregunta -tal como es ¿qué y cómo hacer de otra manera?- se abren nuevas posibilidades. Así, por momentos se logra romper con la pregunta pedagógica, cuya respuesta el docente conoce de antemano y se cuestiona por algo que los/as concierne a todos/as y donde resulta necesaria y genuina la participación de los/as niños/as. Corona Caraveo y Morfín Stoopen advierten que este gesto 
resulta muy dificultoso para la mayoría de los adultos, especialmente en cuanto a reconocer que las reflexiones e intercambios con los/as niños/as tienen algo que aportar (2001). En el intercambio analizado, al interrogarlos como conocedores, los docentes constituyen a los/as niños/as como "seres de palabra" (Masschelein, 2003, p. 67) y como sujetos capaces de participar en un espacio de construcción colectiva con otros/as compañeros/as y docentes. Es posible argumentar, en el sentido de Rancière, que la educación no es la preparación para un futuro, sino que supone la experiencia particular de "ser capaz de" que demuestra la igualdad en referencia a pensar y hablar sobre lo común (Simons y Masschelein, 2011). Si bien la escuela es generalmente construida como un lugar de formación para el futuro, el espacio del Consejo permite reconocer el acto presente y performativo de la educación como un ejercicio de la práctica ciudadana en el aquí y ahora, y que, por lo tanto, se trata de un momento constitutivo de lo político.

\section{Reflexiones finales}

En el presente artículo hemos reconstruido cómo la propuesta de abrir a la participación en una escuela primaria supone mucho más que una estrategia pedagógica de abordaje de la ciudadanía. En esta experiencia se crean, recrean y negocian sentidos diversos en torno a la participación por parte de niños/as y docentes, y de este modo se vuelve una categoría sumamente potente para el análisis de los procesos que apuntan a la democratización de las escuelas.

A lo largo del trabajo se han analizado los debates que se dan con respecto a la pertinencia de la implementación de un espacio de participación: qué alcances puede tener, quiénes se construyen como los "mejores representantes", qué modos son los deseables para participar en el Consejo, etc. Frente a la instauración de un espacio de interlocución común emergen tensiones, resistencias y negociaciones que se generan entre niños/as y docentes por la gestión de un lugar común. También se documenta la capacidad de los/as niños/as como conocedores/as del mundo escolar, y especialmente de aquellas prácticas y momentos que los/as tienen como principales protagonistas: el recreo y sus juegos. Asimismo, los niños/as elaboran disquisiciones sobre qué temas debatir en el Consejo y cuáles omitir, al mismo tiempo que despliegan argumentos fundados en nociones legitimadas que buscan promover juegos que son de su interés. A partir del registro de tales intercambios se puede reconocer cómo, en el debate por ese tiempo y sus actividades, se expresan nociones estructurales en relación con la política, la justicia y la participación, así como los principios de la ciudadanía y la democracia.

A su vez, es posible precisar cómo, al abrir a la participación, también emergen -de modo yuxtapuesto- condicionantes que caracterizan al espacio educativo y que actúan como limitantes a las posibilidades de su apertura, a saber: las ideas y nociones que restringen el reconocimiento de las capacidades de reflexión política de los/as niños/as, las tradiciones históricas autoritarias y normativizantes presentes en el espacio escolar en lo que refiere a la formación de los/as niños/as como ciudadanos/as, y la organización jerárquica que inviste a docentes y directivos de una responsabilidad civil sobre estos sujetos.

Finalmente, a partir de la existencia de un escenario dialógico común, los/as niños/as irrumpen y sorprenden a los/as adultos/as con afirmaciones que los ubican como capaces y conocedores del mundo social que comparten, habitan y construyen cotidianamente en conjunto. En este ejercicio también se reconoce 
cómo los niños presentan otras formas de pensar el espacio y el tiempo del recreo, que evidencian otra experiencia social de esta práctica. De este modo, se visibiliza cómo la participación de estos/as niños/as se vuelve necesaria para la democratización de los vínculos escolares.

\section{Sobre la autora}

Cursa sus estudios de posgrado en la carrera de Ciencias Antropológicas en la Universidad de Buenos Aires. Asimismo, se desempeña como miembro del equipo docente en el Seminario de Investigación Anual con orientación en Antropología y Educación de la Carrera de Ciencias Antropológicas en la misma Facultad.

\section{Financiamiento}

Proyecto UBACyT N. 20020170100417BA: “La comunidad educativa como metáfora de la polis. Conocimiento, protagonismo y temporalidad en la disputa por la constitución de los sujetos", dirigido por Graciela Batallán y codirigido por Silvana Campanini, Programa de Antropología y Educación, Instituto de Ciencias Antropológicas, Facultad de Filosofía y Letras, Universidad de Buenos Aires.

Este documento es resultado del financiamiento otorgado por el Estado Nacional, por lo tanto queda sujeto al cumplimiento de la Ley № 26.899 .

\section{Agradecimientos}

A los evaluadores/as anónimos de este artículo por sus comentarios. A la Universidad de Buenos Aires por posibilitar mi formación en un equipo de investigación con subsidio UBACyT y por otorgarme una beca de doctorado que permite el desarrollo de mi investigación y la escritura de este artículo. 


\section{Q Referencias bibliográficas}

"Achilli, E. (2005). Investigar en Antropología Social. Los desafíos de transmitir un oficio. Rosario: Laborde Editor.

» Adorno, T. (1973). Tabúes relativos a la profesión de enseñar. En Consignas (pp. 64-80). Buenos Aires: Amorrortu.

» Ariès, P. (1987). El niño y la vida familiar en el antiguo régimen. Madrid: Taurus.

» Barna, A. (2012). Convención Internacional de los Derechos del Niño Hacia un abordaje desacralizador. En Kairos. Revista de Temas Sociales. San Luis:Publicación de la Universidad Nacional de San Luís,(29), 1-19

» Batallán, G. (1998) Appropriating ethnography for research in education: reflections on recent efforts in Argentina and Chile. En: Anderson, G. y Montero-Sieburth, M. (Eds.). Educational qualitative research in Latin America: the struggle for a new paradigm. (pp. 3550) Nueva York: Garland

» Batallán, G. (2011). La invisibilidad de los niños y adolescentes en el debate sobre la participación política. Puntos críticos desde una perspectiva histórico-etnográfica de investigación. En G. Batallán y M. R. Neufeld (Comps.), Discusiones sobre Infancia y Adolescencia en Antropología. (pp. 15-24) Colección Antropología y Educación. Buenos Aires: Biblos.

" Batallán, G. (2019). Anthropology and Research Methodology. Oxford Research Encyclopedia of Education.( Septiembre), 1-18. Recuperado de: https://oxfordre.com/education/ view/10.1093/acrefore/9780190264093.001.0001/acrefore-9780190264093-e-354.

» Batallán, G. y Campanini, S. (2008). La participación política de niñ@s y jóvenes-adolescentes. Contribución al debate sobre la democratización de la escuela. En Cuadernos de Antropología Social, 28, 85-106. Recuperado de: https://doi.org/10.159o/0327-3776

» Batallán, G. y Campanini, S. (2012). El presente del futuro ciudadano. Contribución al debate sobre las prácticas políticas de niños y jóvenes escolarizados. En Laborde S. y Graziano A., (Eds). Políticas sociales hacia la infancia. (pp. 41-58) Buenos Aires: Miño y Dávila.

» Batallán, G. y García, J. F. (1992). Antropología y participación. Contribución al debate metodológico. Publicar en Antropología y Ciencias Sociales, 1, 79-89.

"Campanini, S. (2018). Institución escolar y participación de la primera edad de la vida en el debate legislativo en la Argentina contemporánea. Cuadernos de Antropología Social, 47, 143-156.

»Carli, S. (1992). El campo de la niñez. Entre el discurso de la minoridad y el discurso de la Educación Nueva. En: A. Puiggrós (Dir.) Escuela, democracia y orden (1916-1943) (pp. 99-160). Buenos Aires: Galerna.

"Cerletti, L. (2012). “Familias” y “participación”: un análisis comparativo de la Ley 1.420, la Ley Federal de Educación y la Ley de Educación Nacional. Propuesta Educativa, 1(37), 69-77.

» Cigliutti, S. (1993). Los consejos de escuela: un estudio sobre las políticas educativas de convocatoria a la participación de la gestión escolar. Propuesta Educativa, 9, 27-35.

"Corona Caraveo, Y. y Morfín Stoopen, M. (2001). Diálogo de saberes. Sobre participación infantil. México: Universidad Autónoma Metropolitana, Unidad Xochimilco División de Ciencias Sociales y Humanidades Programa Infancia. 
" Castro, L. R. de (2018). "We need to talk about break-time!": The construction of the common by children in school. Childhood and Philosophy, 14(29), 129-148. Recuperado de: https://doi.org/10.12957/childphilo.2018.30560

"Dewey, J. (1978). Educación y democracia. Buenos Aires: Losada.

"Dussel, I. (2005). ¿Se renueva el orden disciplinario escolar? Lectura de los reglamentos de convivencia en la Argentina post-crisis. En Revista Mexicana de Investigación Educativa, 10 (27), 1109-1121. México: Consejo Mexicano de Investigación Educativa

"Enrique, I. (2011). La participación estudiantil en la escuela secundaria en Argentina. Reconstrucción en torno al protagonismo político de los jóvenes (Tesis de Maestría en Políticas Sociales). Facultad de Ciencias Sociales, Universidad de Buenos Aires, Buenos Aires, Argentina.

»Etchegaray, R. (2014). La filosofía política de Jacques Rancière. En Nuevo Pensamiento, 4(4), 25-60.

》Ezpeleta, J., y Rockwell, E. (1983). Escuela y clases subalternas. En Cuadernos Políticos. 37, 70-8o México: Editorial Era

» Jociles, M. I., Franzé, A., y Poveda, D. (Eds.) (2011). El estudio etnográfico de la infancia y de la adolescencia: posibilidades y retos. En Etnografías de la infancia y de la adolescencia. (pp. 9-36) Madrid: Catarata.

" Giddens, A. (1982). Hermeneutics and Social Theory. En: Profiles and Critiques in Social Theory. Contemporary Social Theory. (pp.1-17) Londres: Palgrave

" Golzman, G. y López, D. (1989). Atención: maestros trabajando. Buenos Aires: Libros del Quirquincho.

" Liebel, M. (2007). Paternalismo, participación y protagonismo infantil. En Corona Caraveo Y. y Linares Pontón, M. E. (Eds.) En Participación infantil y juvenil en América Latina (pp. 113-146). México: Universidad Autónoma Metropolitana, Childwatch International Research Network, Universidad de Valencia

» Liebel, M. (2013). Niñez y justicia social. Repensando sus derechos. Chile: Pehuén Editores.

» Masschelein, J. (2003). El alumno y la infancia: A propósito de lo pedagógico. Revista Educación y Pedagogía, 15(36), 61-68

》 Masschelein, J. y Simons, M. (2011). El odio a la educación pública. La escuela como marca de la democracia. En Simons, M., Masschelein, J. y Larrosa, J. (Eds.): Jacques Rancière. La educación pública y la domesticación de la democracia. (pp. 305-342). Buenos Aires: Miño y Dávila.

"Núnez, P. (2013) La política en la escuela: jóvenes, justicia y derechos en el espacio escolar. Buenos Aires: La Crujía.

»Padawer, A., Scarfó, G., Rubinstein, M. y Visintín, M.(2009). Movimientos sociales y educación: debates sobre la transicionalidad de la infancia y de la juventud en distintos contextos de socialización. En Intersecciones en antropología, 10 (1), 41-153.

" Pupavac, V (2001). Misanthropy without borders: The international children's rights regime. En Disasters. 25 (2), 95-112.

" Rancière, J. (1996). El desacuerdo. Política y filosofía. Buenos Aires: Nueva Visión.

"Rockwell, E. (2009) La experiencia etnográfica: historia y cultura en los procesos educativos. Buenos Aires: Paidós

》 Rockwell, E. (2011). Los niños en los intersticios de la cotidianeidad escolar. ¿Resistencia, apropiación o subversión? En Discusiones sobre infancia y adolescencia: niños y jóvenes dentro y fuera de la escuela (pp. 27-52). Buenos Aires: Biblos. 
"Shabel, P. (2016). Venimos a jugar y a luchar. Participación política de niños y niñas en organizaciones sociales. En Revista Lúdicamente, 5 (10), 1-14

»Szulc, A. (2019). Más allá de la agencia y las culturas infantiles. Reflexiones a partir de una investigación etnográfica con niños y niñas mapuche. RUNA, archivo para las ciencias del hombre, 40(1), 53-63.

" Tiramonti, M. G. (1993). Nuevos modelos de gestión educativa: El caso de los consejos escolares de la provincia de Buenos Aires. Propuesta Educativa, 9, 36-49. 